North American Philosophical Publications

\title{
PLURALISM AND NORMATIVITY IN TRUTH AND LOGIC
}

Author(s): Gila Sher

Source: American Philosophical Quarterly, OCTOBER 2020, Vol. 57, No. 4, SPECIAL ISSUE: Alethic Pluralism and the Normativity of Truth (OCTOBER 2020), pp. 337-354

Published by: University of Illinois Press on behalf of the North American Philosophical Publications

Stable URL: https://www.jstor.org/stable/10.2307/48584451

JSTOR is a not-for-profit service that helps scholars, researchers, and students discover, use, and build upon a wide range of content in a trusted digital archive. We use information technology and tools to increase productivity and facilitate new forms of scholarship. For more information about JSTOR, please contact support@jstor.org.

Your use of the JSTOR archive indicates your acceptance of the Terms \& Conditions of Use, available at https://about.jstor.org/terms 


\title{
PLURALISM AND NORMATIVITY IN TRUTH AND LOGIC
}

\author{
Gila Sher
}

ABSTRACT

In this paper I investigate how differences in approach to truth and logic (in particular, a deflationist vs. a substantivist approach to these fields) affect philosophers' views concerning pluralism and normativity in these fields. My perspective on truth and logic is largely epistemic, focusing on the role of truth in knowledge (rather than on the use of the words "true" and "truth" in natural language), and my reference group includes Carnap (1934), Harman (1986), Horwich (1990), Wright (1992), Beall and Restall (2006), Field (2009), Lynch (2009), and Sher (2016a). ${ }^{1}$ Whenever possible, I focus on positive rather than negative views on the issues involved, although in some cases this is not possible.

\section{Pluralism in Truth AND LogiC}

$\mathrm{T}$

he relation between truth-pluralism and logical pluralism has been discussed by a number of philosophers. A natural link between the two is the fact that the main logical (or rather, meta-logical) relation, logical consequence, is defined in terms of truth. A classical reference is Tarski (1936), according to which the sentence $\mathrm{X}$ is a logical consequence of the set of sentences $\mathrm{K}$ iff (if and only if) in every model in which all the sentences of $\mathrm{K}$ are true $\mathrm{X}$ is true too. It is common to say that logical consequence is defined in terms that significantly include preservation or transmission of truth. Now, if truth is plural-that is, there are different types of truth - then the preservation (transmission) of different types of truth might be based on different principles, giving rise to, or requiring, a plurality of logics. This potential connection is laid down in Lynch (2009) and Pedersen (2014), and I share their view. But whether this potential connection materializes depends on what truth-pluralism is and what is required for the transmission of different types of truth. If the plurality of truth is so deep that it allows both realist and antirealist conceptions of truth, and if transmission of realist truth requires, say, a bivalent logic while the transmission of antirealist truth requires a non-bivalent logic, then logic in some fields is bivalent, in others non-bivalent, i.e., there are different types of logic for different fields. ${ }^{2}$ But if truth, as truth, is essentially (hence, always) realist and its plurality is limited to variations within the domain of realist truth (e.g., truth is always based on correspondence but the patterns of correspondence vary in, say, physics and mathematics) $)^{3}$, then the plurality of truth, by itself, would not lead to logical pluralism in the way delineated above.

This, however, does not rule out other connections between truth-pluralism and logical pluralism. For example, both truth and logic might share some traits, or combinations of traits, that are potentially conducive to 
pluralism. And indeed, they both share such a combination of traits, e.g., the combination of having a highly broad and a highly diverse scope. Both apply to many fields of knowledge, including fields that vary in their subject-matter and degree of abstractness. This opens up the possibility of pluralism for both.

But diversity and breadth by themselves do not necessitate pluralism. In this paper I would like to explore a pair of other factors that correlate with pluralism and its opposite, monism, factors whose correlation with pluralism and monism in truth and logic has not been examined before. These factors pertain to our attitude to, or conception of, truth and logic, specifically, whether it is deflationist or substantivist. Starting with truth, I will examine whether and how deflationism and substantivism, as well as variations within substantivism, lead to different views on pluralism with respect to truth.

Before turning to this question, however, let me briefly clarify the "level" on which I will speak on truth in this paper, for example, whether I will talk about the concept of truth or about the property of truth. This distinction plays a significant role in some philosophers' thinking about truth, but it plays a less significant role in my own thinking about it. One reason is that for me philosophically important concepts are denoting concepts, so that given the philosophical importance of the concept of truth (in my view), truth is not just a concept. Another is that it is not automatically the case that if the concept of truth denotes something, it denotes a property. A further alternative is that the concept of truth denotes a norm, and there are other options as well. For reasons that I will explain below, I regard truth itself (what the concept of truth stands for) primarily as a norm and secondarily as a property - the property of satisfying the norm of truth. So, for me, talking about the concept, norm, and property of truth are all significant.
Very often in this paper, though, I use "truth" to talk about the subject-matter of philosophical investigations and theories of truth. Although different philosophers have different views about what this subject-matter is, there is a certain family resemblance between the range of views discussed in the philosophical literature, and it is our familiarity with (more or less) the same literature that enables us to talk to each other about truth even when our answers to the question "What is truth?" differ significantly.

\section{A. Pluralism and Monism with Respect to Truth}

One well-known "manifesto" of truthdeflationism (often called "alethic deflationism") is Horwich (1990). Horwich uses the term "minimalism" for his particular version of deflationism, but here I will treat this version as representative of the deflationist approach. It is easy to see that deflationism is associated with, or leads to, monism with respect to truth. According to deflationism, there is very little to truth: truth is a very thin property, concept, or predicate, and all there is to it is fully captured by the equivalence schema, formulated by Horwich as:

(E) It is true that $p$ if and only if p. [Horwich $1990,7]^{4}$

Now, because this understanding of truth is both minimalist and exhaustive, it leaves no room for pluralism with respect to truth. Suppose there were some significant differences between truth in physics and truth in mathematics. These differences would concern features of truth other than (E), but deflationism does not recognize any such features. From the deflationist's perspective, either there cannot be such differences or, if there could be, they would be irrelevant to our understanding of truth. The result is monism with respect to truth. Given any two fields of knowledge in the scope of truth, $\mathrm{K} 1$ and $\mathrm{K} 2$, their concept of truth is exhausted by (E). ${ }^{5}$ 
Deflationism is too undiscerning to discern differences between fields of truth. Instead of looking and seeing whether truth behaves in the same way in all fields, deflationists limit their attention to a single, minimalistic test, one that is blind to any potential differences between truths in different fields. Generalizing, we may say that an easy way to impose unity (monism) on truth is to limit our attention to a very thin common denominator of all truths (e.g., (E)).

But this way is too easy. One problem with the monistic conception of truth arrived at in this way is that it is blind to philosophically significant differences between truths. One example of such a difference is the difference between material truth (truth simpliciter) and logical truth. ${ }^{6}$ The difference between these two types of truth is difficult to ignore, but from a deflationist perspective, which takes only the material (E) schema into account, there is no room for two types of truth. Horwich (1990) does not say anything about logical truth, but he does say that "a central tenet of the point of view advanced here is that the theory of truth and the theory of logic have nothing to do with one another" (Horwich 1990: 76-77). This suggests that he does not recognize logical truth as a specific type of truth. $^{7}$

In contrast to Horwich, Wright (1992), Lynch (2009), and I (2016a) are all substantivists with respect to truth. By "substantivist" I mean an advocate of a substantive theory (of any subject-matter), and by "substantive" I understand, in addition to "non-deflationist," also having such traits as "informative," "explanatory," "deep," "important," "significant," "theoretically grounded," "subject to high standards of discovery and justification," "rigorous," "systematic," "thorough," "of intellectual interest," and so on. Non-deflationism by itself may be viewed as weak substantivism; the aggregation of all or most of the traits noted above is strong substantivism. ${ }^{8}$ Wright's, Lynch's, and my substantivism about truth explains (at least in part) our attention to the plurality of truth. If truth is not exhausted by a single and simple principle, if there is more to truth than the equivalence schema, then there is room for multiple principles of truth, including principles that vary in scope. Some principles may hold in all domains of truth, others may be specific to particular domains (clusters of domains). Given the breadth of truth and the diversity of fields of truth, substantivism is open to the possibility of multiple types of truth with principled differences between them. For example, some principles governing truth in everyday physics (the physics of mid-size, observable objects) might not govern truth in mathematics, and vice versa.

The acceptance of plurality by any theory, however, requires a balance between unity and diversity (disunity). And one way to introduce such a balance is to include both general and particular (global and local) principles. The former unify the theory, the latter diversify it. But the balance between unity and plurality might vary in different theories. The plurality of truth in some theories might be deeper than in others, and this, indeed, is the case in the substantivist theories we are examining. Whereas Wright and Lynch allow truth in some fields to be based on principles of one kind-for example, correspondence - and in others on principles of an altogether different kind-for example, coherence-I restrict the plurality of truth to correspondence principles. Truth in all fields is based on correspondence, but the patterns of correspondence may vary from field to field.

What is the source of this difference? One source is diverse attitudes toward the general principles of truth. If one construes the general principles as highly demanding, substantive principles, this reduces the options left open for special (local) principles of truth. For example, if one demands that truth in all fields be based on substantive 
correspondence principles, this rules out weaker types of truth-for example, coherence truth-in any field. But if the general principles are weak and nonsubstantive, this leaves room for radically diverse principles of truth in different fields. Wright and Lynch conceive of the general principles of truth as relatively weak and unsubstantive. They characterize these principles as platitudinous, and Wright regards his overall approach to truth as minimalistic as a result. In contrast, I view the general principles as substantive and highly restricting, hence limiting the scope and depth of the plurality of truth. All of us view correspondence as a general principle, but while Wright and Lynch view it as sufficiently weak to be compatible with mere coherence in some areas, I view it as strong enough to rule out mere coherence and other relatively weak types of truth (e.g., mere pragmatic truth) in all areas.

This difference in attitude toward the general principles is not accidental. It reflects differences in motivation and overall goal. Wright (1992), for example, approaches truth from the perspective of the realism-antirealism debate, and especially from Dummett's viewpoint on this debate (see, e.g., Dummett 1963). The question of realism, according to Dummett, is relative to a field or area of discourse, and one may be a realist with respect to one field (e.g., everyday physics) and an antirealist with respect to another (e.g. mathematics). Wright seeks to clarify confusions in the realism-antirealism debate by focusing on truth. His main claim is that truth-aptness, by itself, does not distinguish between realism and antirealism. Both realists and antirealists can adhere to the general, minimalistic principles of truth, but only realists (with respect to a given field) can adhere to strong local principles of truth such as robust correspondence. Lynch approaches truth from a different direction. Noting that the main difficulties with the traditional correspondence theory of truth arise from the existence of fields in which correspondence, in the traditional sense (copy, isomorphism), does not seem to hold, he raises the question: Is truth one or many? His answer is that it is both. It is one in sharing the same general, platitudinous principles, and it is many in having different substantive principles (correspondence, coherence) in different fields. ${ }^{9}$

My own starting point is the role of truth in knowledge. ${ }^{10}$ Knowledge qua knowledge is directed at some subject-matter-some facet of the world (broadly understood) — and its goal, or one of its main goals, is to get this facet of the world right. But knowledge-especially theoretical knowledge-also aims at substantive (informative, explanatory) understanding and is therefore subject both to a strong norm of truth and to a strong norm of substantiveness. Since knowledge is always knowledge of the world (some facet of the world), its norm of truth is always a correspondence norm. ${ }^{11}$ But since we always aim at correct knowledge, in a strong sense of correctness, the universal correspondence norm is a substantive, highly demanding norm, a norm that cannot take the form of mere coherence or warranted assertibility in any field. ${ }^{12}$ The complexity of the world, however, combined with the complexity of human cognition, requires a certain degree of flexibility with respect to the "route" of correspondence, that is, with respect to the structure or pattern of the connection between true truth-bearers and those facets of the world they are true of. Some facets of the world are easy for us to access, others are difficult. Some we have sensory access to, others we do not; some we can access directly, others require indirect access; some we can access through simple routes, others demand complex routes. From the point of view of correctness, it does not matter whether the correspondence between a given theory (or statement) and its target in the world is direct or indirect, simple, or complex. As long as our theories are connected to the world in a way 
that ensures that what they say about it is the case, the complexity of this connection does not detract from their truth. For that reason, the more we wish to know, both in terms of diversity and in terms of depth, the more flexible we must be with respect to "routes of correspondence" (as well as with respect to routes of discovery and justification more generally). Correspondence is a universal and highly demanding norm, yet to maximize knowledge, we must be granted freedom in implementing it. The result is pluralism within the bounds of correspondence. ${ }^{13}$

Conclusion: Our analysis suggests that (a) deflationism is conducive to monism while substantivism is open to pluralism, and (b) a weaker substantivism leads to a stronger pluralism than a stronger substantivism. The key to deflationist monism is the combination of a weak understanding of truth and a uniqueness requirement: (i) there is a weak principle of truth, namely (E), and (ii) this principle is the only principle of truth. (i) and (ii) together imply that truth is blind to anything but a certain weak feature common to all truths, hence it cannot discern any differences between truths with respect to their type (e.g., material vs. logical) or field (e.g. everyday physics vs. mathematics). Substantivism, in contrast, is open to pluralism. But substantivist pluralism can be stronger or weaker (e.g., sanctioning both correspondence truth and coherence truth or sanctioning only correspondence truth yet allowing a plurality of patterns of correspondence). One way to restrain truth-pluralism is to adopt substantive, highly restrictive, general principles of truth. The more substantive and restrictive the general principles are, the fewer options they leave for local variations in truth; the less substantive and restrictive they are, the greater and deeper the pluralism they sanction. ${ }^{14}$ An optimal theory of truth, in my view, is one that goes far enough in its investigations to recognize both the diversity of truth and the limits of this diversity.

\section{B. Pluralism and Monism with Respect to Logic}

Logical pluralism has been widely discussed lately, following the publication of Beall and Restall's 2006 book on this topic. But the roots of this position go back to Carnap in the early twentieth century.

Carnap (1934) $)^{15}$ is a conventionalist with respect to logic, and his conventionalism has both a descriptive and a normative dimension. Descriptively, it says that logic consists of a set of conventions for using language; normatively, it proclaims that only pragmatic considerations play a role in choosing a logic. It follows that there is no question of correctness in logic, hence no question of truth and falsehood with respect to it. The claim that sentence $\mathrm{X}$ follows logically from the set of sentences $\mathrm{Y}$ is neither true nor false: it is merely convenient or inconvenient, justified or ruled out on pragmatic grounds. This characteristic is closely related to Carnap's pluralism. There are very few constraints on our choice of a logic, and these constraints are largely weak. As a result, many different logics can satisfy our constraints, and none is inherently superior to the other. We may say that for a pragmatist-conventionalist, anything goes with respect to logic, modulo convenience.

Carnap's pluralism is also closely related to his principle of tolerance. But it is important to note that this principle, by itself, is not sufficient for logical pluralism. Tolerance is an attitude one can adopt in any field, but Carnap does not recommend tolerance in fields where there is a question of right and wrong, correctness and incorrectness, truth and falsehood, such as physics. We should not be tolerant of erroneous physical theories. It is only in areas where pragmatic considerations prevail that tolerance is relevant to choice of theory. It is thus primarily Carnap's pragmatist conventionalism, rather than his tolerance, that is responsible for his logical pluralism.

Unlike Carnap, Beall and Restall (2006) do set correctness constraints on logic. They 
accept the Tarskian definition of logical consequence which says that " $\mathrm{X}$ is a logical consequence of $\mathrm{Y}$ " is true only if the truth of the sentences in $\mathrm{Y}$ is preserved by (or is transmitted to) $\mathrm{X}$ in all cases, and this delimits the class of admissible logics in a way that does not depend on pragmatic considerations, hence rules out, in principle, at least some Carnap-admissible logics.

But Beall and Restall do not specify either the relevant sense or the scope of "all cases," and this opens the door to multiple logics, logics that differ in their construal of "all cases." That is the crux of their logical pluralism. To understand their view, then, we have to understand why they do not specify the sense/scope of all cases. Unfortunately, it is not easy to find a substantial justification for their decision to leave the scope of all cases open. Three candidates for such a justification are:

(a) Leaving the scope of "all cases" open enables us to make sense of current practice: "[L]ogical consequence can be (and has in fact been) settled in more than one way [with respect to 'all cases']" (Beall and Restall 2006, 28).

(b) Leaving the scope of "all cases" open enables us to do justice to the "appearance" (Beall and Restall 2006, 30) that there is more than one sense of "validity" or 'follows from"” (Beall and Restall 2006, 30). Consider the argument " $A \wedge \sim A$; therefore $B$." "On the one hand, there is no consistent case in which $A \wedge \sim A$ is true but $B$ untrue; hence the argument is valid, at least in one (seemingly admissible) sense. On the other hand, there is also a sense in which $B$ does not follow from $A \wedge \sim A$, as the former has 'nothing to do with' the latter. Hence, ... the argument ... is invalid" (Beall and Restall 2006, 30) So it appears that there are two equally legitimate notions of "validity" or "follows from," hence room for (at least) two legitimate logics. Beall and Restall are aware that "appearances . . . sometimes deceive" (Beall and Restall 2006, 31). But they point out that both conceptions satisfy "the core notion" of logical consequence underlying "validity" and "follows from," where the "core notion" (Beall and Restall 2006,31 ) includes, in addition to preservation of truth under all cases, also necessity, normativity, and formality. This further supports the legitimacy of both conceptions.

(c) Leaving the scope of "all cases" open leads to a view-logical pluralism-that has certain virtues of its own, including the pragmatic virtue that "the plurality of consequence relations comes at little or no cost" and the moral virtue that it "affords a more charitable interpretation of many important (but difficult) debates in philosophical logic than is otherwise available" (Beall and Restall 2006, 31).

However, the justificatory force of these points is jeopardized by the fact that Beall and Restall do not engage in a thorough and substantive investigation of the philosophical ramifications of the Tarskian constraint on admissible logics. As a result, it is perfectly possible that there are constraints on admissible logics, including constraints on the scope of "all cases," that they simply do not come upon because their investigation of the Tarskian conception of logical consequence is so minimal. Essentially, they limit themselves to a few surface platitudes about logical consequence, never going beyond them. For example, they do not investigate whether some non-trivial conditions have to be satisfied for the appropriate kind of truth to be transmitted (preserved) from premises to conclusion. (If the kind of truth required for genuine knowledge is correspondence, then, since it makes stronger demands on the relation between language and the world than, say, coherence, it might be more difficult to transmit.) Nor do they investigate whether and how logical necessity differs from other types of necessity, e.g., nomic necessity (the necessity of physical laws), and how this affects the scope of "all cases." And so on. Such investigations might result in further constraints on the scope of admissible 
logics, restricting the plurality of logic in a non-trivial way.

My own investigations (2016a) do lead to further constraints. My starting point is the role of logic in knowledge. Due to our cognitive limitations on the one hand and our epistemic ambitions on the other, we seek a powerful method of expanding our knowledge through inference. Such a method will enable us to transmit truth - the kind of truth involved in genuine knowledge of the world, namely, correspondence truth-from sentences to sentences universally and with an especially strong modal force. But not just any proposed logic will satisfy this requirement. That is, not just any logical "game," or any system of rules, will give rise to correct claims of what follows logically from what. To separate correct and incorrect logical theories (correct and incorrect claims of logical consequence) we need to understand the conditions under which a given rule in fact guarantees the transmission of correspondence truth from premises to conclusion universally and with the designated modal force.

Consider two sentences, S1 and S2, and suppose that $\mathrm{S} 1$ is true iff the condition $\mathrm{C} 1$ is satisfied by the world and $\mathrm{S} 2$ is true iff the condition C2 is satisfied by the world. Suppose further that the world is such that satisfaction of $\mathrm{C} 1$ rules out satisfaction of $\mathrm{C} 2$. Then any logical theory which says that $\mathrm{S} 2$ is a logical consequence of $\mathrm{S} 1$ is incorrect. For example, suppose that, as most of us believe is the case, there is (or at least could be) more than one object in the world. Then a logical theory that includes a rule that conflicts with this fact-for example, the rule "from ' $\Phi \mathrm{a}$ ' and ' $\mathrm{a} \neq \mathrm{b}$ ' derive ' $\Phi \mathrm{b}$ '”- is incorrect. Similarly, if logic requires an especially strong modal force and the world is such that satisfaction of $\mathrm{C} 1$ does not necessitate, with a considerable modal force, satisfaction of $\mathrm{C} 2$, a logical theory which says that $\mathrm{S} 2$ is a logical consequence of S1 is incorrect. No matter how tolerant we wish to be, we cannot admit just any theory of logical consequence (or a theory that satisfy just any conditions on "all cases").

Investigating logical consequence in greater depth than Beall and Restall is thus likely to move one closer to logical monism. It might lead one to realize that for a given candidate for a logical system to be admissible it must, for example, comply with certain requirements concerning the world. An admissible logic must take certain features of the world into account. This will limit the scope of admissible logics.

One general argument in favor of this view is given in Sher (2016a). I will not be able to describe this whole argument in detail here, but a rough sketch of one part of the argument, related to the last paragraph, should suffice to give its flavor. Suppose that a given candidate for a logical system, L, does not take the structure of the world into account, and that according to L, S2 is a logical consequence of S1. Suppose in addition that truth in general is based on correspondence and that, as above, $\mathrm{S} 1, \mathrm{~S} 2$ are true iff the conditions $\mathrm{C} 1$, $\mathrm{C} 2$ respectively are satisfied by the world. Now, we know that in the world satisfaction of some conditions rules out satisfaction of other conditions. Suppose, as above, that satisfaction of $\mathrm{C} 1$ rules out satisfaction of $\mathrm{C} 2 .{ }^{16}$ No matter how attractive $\mathrm{L}$ seems to be, the world rules it out as an admissible logic. An admissible logical theory is constrained by the world.

Further investigations might lead us to require that "all cases" be very broad, for example, include all formally-possible cases (in a certain sense of formal possibility — see Sher 1996, 2016a). ${ }^{17}$ This will further narrow the scope of admissible logics.

I should add, however, that even these results do not rule out logical pluralism altogether. First, the world itself might be formally diverse in one way or another (e.g., the formal laws governing the physical world on 
the microscopic level might vary from those governing it on the macroscopic level). Second, even if the world itself is monistic, we, humans, might be incapable of developing a unified theory of its formal structure. In this case, too, it would be rational for us to accept a plurality of logics. Third, we, humans, have multiple goals, and different goals might lead to different logic-like theories, based on different principles and constrained in different ways. Finally, we may share Carnap's view that the development of new logics is in any case a worthwhile enterprise, because it encourages innovation and potentially leads to new discoveries. Thus, both considerations concerning the world and epistemic considerations leave the door open to some types and degrees of logical pluralism.

Conclusion: There are certain similarities between logical pluralism and truthpluralism. Our position with respect to both pluralisms significantly depends on (i) how active or passive we are in investigating their subject-matters, i.e., whether we do, or do not, take into account the implications of thorough investigations of logic and truth, and (ii) how demanding the general principles governing logic and truth are. The less we investigate truth and logic beyond what they appear to us to be, the less likely we are to discover constraints on admissible theories about them. And the more demanding their general principles are, the more constraints they set on the plurality of such theories. In general, the more we find out about a given subject-matter and the more we care about correctness, the more discriminating we are with respect to admissible and inadmissible theories about that subject-matter.

\section{Normativity IN TRUth AND Logic}

Both truth and logic are traditionally viewed as highly normative, telling us how we ought to think, theorize, and reason. But in recent decades this traditional view has been challenged by several philosophers, for example, Horwich (1990) in the case of truth and Harman (1986) and Field (2009) in the case of logic.

\section{A. The Normativity of Truth}

In his (1990) book Horwich does not discuss the normativity of truth as such, but philosophers generally interpret his view, and the deflationist view more generally, as leaving no room for a significant normative role for truth. In a recent paper, Horwich confirmed this view: "My answer [to the question 'Is TRUTH a normative concept?' is] "no"" (Horwich, 2018). Some critics find Horwich's view of truth exceedingly narrow just on the ground that it neglects the normativity of truth or has an unduly weak conception of its normativity. Wright (1992), for example, criticizes deflationism on this ground. The deflationist view, as exhausted by the equivalence schema-or, on Wright's reading, by the disquotational schema ${ }^{18}$ cannot distinguish between assertions satisfying the norm of warranted assertibility and assertions satisfying the norm of truth. To do so, we require additional principles, for example, the principle that "a statement may be justified without being true, and vice versa" (Wright 1992, 34). But if the deflationist view adds this, or a similar principle, it is no longer limited to the equivalence (disquotational) schema, hence it loses its deflationist character. I think Wright is right, but his argument touches on only one aspect of the problem.

In my view (2016a), the normativity of both truth and logic is grounded in their roles in our cognitive life. For Horwich, the role of truth is minimal and purely technical. The main reason we, humans, need a concept of truth is that the predicate associated with this concept enables us to make assertions that would be more difficult to make without it. For example, if we do not know the details of Einstein's theory, it is difficult for us to assert it; but using the truth predicate we can easily 
assert it indirectly, namely, by saying "Einstein's theory is true." It is also difficult for us to assert all instances of the law of excluded middle, since it has infinitely many instances, but we can indirectly assert all these instances by saying "All sentences of the form ' $P$ or not $P$ ' are true." 19 A concept limited to this role is a purely technical, non-normative concept.

This, however, is not the only, or even most important, role of the concept of truth in our cognitive life. Before explaining why, let me contrast Horwich's conception of normativity with a different conception, due to Korsgaard. Korsgaard (1996) explains the generation of normative concepts as follows:

Normative concepts exist because human beings have normative problems. And we have normative problems because we are self-conscious rational animals, capable of reflection about what we ought to believe and to do. That is why the normative question can be raised in the first place: because even when we are inclined to believe that something is right and to some extent feel ourselves moved to do it we can still always ask: but is this really true? and must I really do this? . . . It is . . because we are normative animals who can question our experience, that normative concepts exist. ... $[\mathrm{N}]$ ormativity is a problem for human beings because ... it is always possible for us to call our beliefs and motives into question. [Korsgaard 1996, 46-49]

Horwich is not interested in this perspective on normativity. His approach is far narrower. "A concept is normative," he says, "iff a person can fully possess it only in virtue of deploying the concept OUGHT" (Horwich, 2018). Two examples of paradigmatically normative concepts are "ought" itself and "good." But "truth," Horwich says, is different from these concepts. This indeed is the case if "truth" is a purely technical concept. But Horwich does not make this point. Comparing "truth" to concepts like "umbrella," he says that in the same way that we can fully possess the concept of "umbrella" without deploying "ought," we can fully possess "truth" without deploying it.

This argument, however, is problematic. First, the comparison of truth to umbrella is unreasonable. Truth, unlike umbrella, is not a thing; and umbrella, unlike truth, is not a standard. Second, while Horwich is right in saying that normative concepts are "ought" concepts, ${ }^{20}$ truth does satisfy this requirement: "[a]ny law asserting what is, [i.e., any true law] can be conceived as prescribing that one ought to think in conformity with it" (Frege 1893, 12, my italics), ${ }^{21}$ and this extends to any true statement (proposition, belief, etc.).

To further understand the normativity of truth, we may focus on (a) the origins of truth in the basic human cognitive-epistemic situation, (b) the conditions under which truth arises in our cognitive life, and (c) the role of truth in justification. ${ }^{22}$ Briefly, the normativity of truth can be explained as follows:

(a) The basic human cognitive-epistemic situation is characterized by a tension between our epistemic ambitions and our cognitive shortcomings. On the one hand, we, humans, seek to know the world in all its complexity. On the other hand, we have serious cognitive limitations. Furthermore, even our cognitive endowments may add to these tensions. For example, imagination is an important cognitive resource, yet it tends to blur the line between fiction and reality. These inherent tensions make correctness a major issue for us. Had we either perfect cognitive access to the world or no cognitive access at all, or had we no serious interest in knowledge of the world, we would have had no use for norms of correctness. But given our imperfect yet powerful cognitive resources and our ambitious epistemic desires, norms of correctness are indispensable for us. This suggests that truth is first and foremost a norm of correctness, and therein lies its immense epistemic value. Horwich rightly says that the question of what we can, do, 
and should believe is a question about the world on the one hand and our cognitive access to it on the other. But he says that this has nothing to do with truth. And in this he is wrong. Given the basic human situation, it has everything to do with truth, understood as a standard of correctness. ${ }^{23}$ Once we have a concept of truth at hand, we can use it for other purposes as well, including the technical purpose pointed out by Horwich. But this purpose is not one of its most salient purposes.

(b) Under what conditions does truth-the idea, concept, norm of truth-arise in our cognitive life? What modes of thought are required for truth to arise? In Sher (2004, 2016a) I observed that truth arises at the juncture of three fundamental modes of thought: the immanent, transcendent, and normative modes. To arrive at truth we need, first, to direct our cognitive gaze at the world, or at some thing in the world, and say something about it, or attribute some property (relation) to it. I call this the "immanent" mode of thought, the mode of thought we use when we speak from within a theory. Immanent thoughts are the bearers of truth and falsehood.

But immanence by itself is not sufficient for truth. To arrive at truth, we need to transcend our immanent thoughts and hold in view both these thoughts and their subjectmatter, or those facets of the world they are directed at. We then arrive at a transcendent standpoint, a standpoint from which we can talk about our immanent thoughts in their relation to the world. ${ }^{24}$

Transcendence by itself, however, is still not sufficient for truth. By assuming a transcendent standpoint, we can ask many questions about our immanent thoughts, not just truth questions. For example, we can ask whether a given immanent thought refers to its subject-matter directly or indirectly, whether it describes it briefly or at length, and so on. To ask questions of truth we need to assume a normative mode of thought. In this mode we can ask critical questions about our immanent thoughts in relation to the world: Do they get the world right? Do objects in the world have the properties (relations) they attribute to them? Etc. These are the normative questions of truth, and to say that a thought is true is to give a positive answer to these questions. ${ }^{25}$

(c) A norm of truth is essential for other norms as well, for example for the norm of epistemic justification. Consider justification in general. We are called on to justify many things: our actions, decisions, choices, beliefs, theories, assertions, and so on. How we justify our actions, for example, depends on many things: our goals, needs, desires, values, and other norms we hold. The same action can be justified or unjustified depending on what these are. If my goal is to break the world record in some sport, I will be justified in spending much of my time exercising. But if my goal is to solve open problems in mathematics, I will probably not be justified in spending as much time on physical exercise. Or consider lying. Whether I regard an instance of lying as justified or not may depend on my values and norms. The same instance of lying might be viewed as justified by a person whose norms do not include honesty, unjustified by a person whose norms do include honesty. Now, given the conception of knowledge delineated above, with its emphasis on the world and its goal of correctness with respect to the world, epistemic justification requires something like a norm of correspondence truth (rather than a norm of, say, entertainment) to guide it.

But that is not all. Veridical justification requires not just the general idea of truth, but also substantial truth conditions. To justify a claim $X$, we need to know the conditions that have to hold in the world for $\mathrm{X}$ to be true, that is, we need to know the truth conditions of $\mathrm{X}$. Not the disquotational truth conditions of $\mathrm{X}$, but its substantial truth conditions. This is especially important in justifications of advanced scientific theories, which is often indirect. To justify the claim that, say, Higgs Boson particles exist, we rely on indirect experiments, such 
as those carried by the CERN Large Hadron Collider. But for such experiments to justify the claim that Higgs Boson particles exist, we have to connect their results, or the forms in which they are presented to us (e.g., by numbers, or by pictures on a computer screen) to the conditions that must hold in the world for this specific claim to be correct, i.e., to the truth conditions of this claim. To be useful, these truth conditions cannot be simply disquotational; they have to be substantive, i.e., specify the distinctive characteristics of the particles in question. Truth, then, is doubly normative for epistemic justification: it is both a general and a specific guiding norm for it. It is the former through its general connection with correctness, and the latter through the informative ways it connects specific statements to their target in the world. The points raised in (a)-(c) provide reasons for viewing truth as a norm.

To summarize: One of the main factors in the disagreement between deflationists and substantivists about the normativity of truth is the scope of their interest in truth. It is easy for a deflationist to miss the normativity of truth because of his purely technical interest in it. One has to have a broader interest in truth to recognize its normativity.

\section{B. The Normativity of Logic}

Logic is traditionally thought to be a normative discipline par excellence. But in recent decades this view has been challenged by a number of philosophers. Harman (1986), for example, challenges the connection between logic and rationality. He arrives at this challenge by approaching logic from the perspective of everyday reasoning and belief revision. What norms is it rational for an actual person in her everyday life to adopt? Is it rational for her, given her overall goals, limitations, and constraints, to treat logic as normatively binding, no matter what? His answer to this question is negative. To justify this answer, he points to several problems with treating logic as normatively binding.
Following Steinberger (2017), I will note four of these problems: (a) Just because I believe $\mathrm{P}$ and I believe that $\mathrm{Q}$ follows logically from $\mathrm{P}$, does not mean that I am bound to believe Q. Sometimes it is more rational to stop believing P than to believe Q. (b) Many logical consequences of our beliefs are completely useless for us. Believing them merely clutters our mind. (c) "Ought" requires a physical-psychological "can," but the logical "ought" does not imply such a "can." (d) Inconsistency is sometimes rational. One of Harman's examples is the preface paradox: It is rational for me to believe of each claim in my book that it is correct, yet that there are some mistakes in my book. Another possible example comes from science. One can view the particle-wave duality in physics as introducing a certain logical tension. Are quantum-scale objects particles or nonparticles? It might seem that they are both. All these problems are said to show that logic is not, and should not be, normatively binding.

What is Harman's underlying view of logic? Harman views logic as a theory of logical consequence (or implication) in the sense of preservation of truth from premises to conclusion with a strong modal force. In my view, Harman is right in characterizing logic in this way. But unlike Harman, I think that this characterization points to the very trait that makes logic a normative discipline. Given our epistemic ambitions on the one hand and our limitations on the other, a strong method of logical consequence (in the above sense) is of great importance for us. Such a method guides us in expanding as well as correcting our knowledge (theories), and as such it is strongly normative for us. But what about the problems raised by Harman? I think these "problems" pose no real obstacle to the normativity of logic. They arise for Harman because his conception of normativity is at once too narrow and too strong to account for the normativity of logic. It is too narrow in focusing on single individuals in their day to 
day life. And it is too strong in requiring absolute obedience to norms. In my opinion, logic is normative for us not just, or mainly, in our everyday life, but also, and most importantly, in our role as seekers of knowledge, including theoretical knowledge. As a result, logic is normative for our theories of the world, and this normativity is not affected by any of the problems raised by Harman. On this view, we may respond to (a)-(d) above as follows: (a) Logic's normativity licenses not just the extension of our theories but also their revision: if our theory implies $\mathrm{X}$ and $\mathrm{X}$ is false, we are called to revise it rather than extend it by adding X. (b) A mind may be cluttered by too much information, but a theory is not a mind. A theory is not an object engaged in thinking, an object whose thinking might be impaired by having too much information. The worry of clutter due to logical consequences simply does not apply to things like theories. Furthermore, (c) to require a theory to include its logical consequences is not to require either the theory itself or its creators and users to be aware of all its consequences. A theory is not the kind of thing that has awareness, and we may view a theory as including a myriad of logical consequences without viewing either its builders or its users as aware of all these consequences. Finally, (d) Harman's conception of normativity as requiring that if $\mathrm{X}$ is normative for a person Y, then Y must fully comply with $\mathrm{X}$ no matter what, regardless of circumstances and other norms, is unreasonable. Norms play an important role in our lives, but our relation to our norms is not one of full and absolute compliance or no compliance at all. We are bound by many norms and our norms often compete with each other. In some circumstances one norm is more binding than another, in others the second is more binding than the first. Furthermore, often, the requisite conditions for acting with absolute compliance with a given norm do not hold. And in some situations it might even be normative to disobey certain norms, at least for the time being. For example, given the current state of our physical knowledge, it may very well be normative for us to preserve the particle-wave duality even if we regard it as causing logical tension in our physical theory. Eventually, we will have to eliminate this tension, but under certain circumstances, it is reasonable to accept it. ${ }^{26}$ Thus viewed, $\mathrm{X}$ may be normative for us without requiring complete and absolute compliance by us. ${ }^{27}$

The normativity of logic, as I noted above, is intricately connected with its role as a theory of transmission (preservation) of truth with a strong modal force. But the view that logic is capable of playing such a role has recently been challenged by several philosophers. One of these is Field (2009). Field's challenge is based on features of the specific background theory used to define the notion of "preservation of truth with a strong modal force," namely, ZFC. For logic to be a theory of preservation of truth with a strong modal force, it has to categorize a sentence $\mathrm{X}$ as logically true only if it is both (i) actually true, and (ii) necessarily true. But logic fails to satisfy this requirement. Why? Logic categorizes $\mathrm{X}$ as logically true iff it is true in all models. But the totality of models is too limited to guarantee satisfaction of (ii) and in some cases also of (i). In what way is the totality of models too limited? It is too limited in being restricted to set-models, i.e., models with universes restricted to proper sets. Since class-models are intuitively possible, logic fails to satisfy the necessity requirement, (ii). Furthermore, let $\mathrm{X}$ be a set-theoretic sentence (i.e., a sentence formulated in the language of set theory, or a sentence about sets). Since logic is topic neutral, its test of logical truth must apply to $\mathrm{X}$. Suppose $\mathrm{X}$ is true in all models. This does not guarantee that $\mathrm{X}$ is actually true. The universe of sets is a proper class, but no model represents this universe, since models have only proper sets 
as universes. No model, therefore, represents the actual world of sets, and as a result, truth in all models does not guarantee the actual truth of X. In this way logic fails to satisfy the actual-truth requirement, (i).

I believe this challenge is based on an unreasonable understanding of the claim that logic is a theory of preservation of truth with a strong modal force. This claim is not tied up with any of the specific features of ZFC that give rise to Field's challenge. $\mathrm{ZFC}$ is no more than one optional tool for precisifying this claim. The lesson to draw from Field's challenge is that in presenting a philosophical claim about logic we have to separate our general philosophical considerations from particular precisifications of these considerations within a specific background theory. The general philosophical theory is immune to the problems of a specific precisification, like those concerning sets and classes.

One might argue that any precisification will have some problems, and this is probably correct. No theory is perfect; therefore, any precisification within a specific background theory is bound to have some weaknesses. But it is important to emphasize that not all precisifications suffer from the same problems, and in particular, we have no reason to believe that all possible precisifications of our account of logic will suffer from the same problems as those raised by Field. ${ }^{28}$

Furthermore, the anticipation of some problems or other in any precisification does not mean that we should not precisify our ideas. It is worthwhile to give a precise form to our ideas using precise formulations, but it is also important to realize the limitations of such precisifications. Moreover, it is important to realize that theories, including background theories, change and develop in time, so that a current weakness of a specific background theory might be overcome in the future. In Sher (2013; 2016a) I make a point of dividing my account of logic into two parts: a general philosophical account which is independent of ZFC and a specific rendition of this account which is not. ${ }^{29}$

What, then, is the source of the normativity of logic on my account and how (or in what sense) is the normativity of logic stronger than the normativity of other disciplines? The two main sources of the normativity of logic, in my view, are (a) its role in knowledge, and (b) the truth of the logical laws. We have seen that the role assigned to logic in knowledge is normative; hence logic is "functionally" normative. And as pointed out by Frege (see above), truth in general is a source of normativity. Hence the truth of the logical laws is another source of its normativity. How do we explain the special strength of the normativity of logic? By reference to its "semantic" formality (see Sher 2016a). Just as the normativity of physics is due to truths about physical laws, the normativity of logic is due to truths about formal laws. And it is a special feature of formal laws - their especially strong degree of invariance (to be explained below) - that is responsible for the special normative force of logic, that is, for the fact that its normativity is in a certain significant sense greater than that of physics and biology and most other disciplines.

What are formal laws? Formal laws are laws governing formal properties (relations) of objects. Formal properties are properties that are sensitive only to patterns of individuals having properties and standing in relations, but not to the identity of those individuals (who those individuals are). If you replace the individuals in a given domain in a 1-1 manner, a formal property (relation) will not notice. Formal properties are invariant under 1-1 replacements of the underlying individuals (more precisely, the individuals in the underlying domain). For example, the (1st-level) identity relation does not distinguish between one pair of individuals and another, generated from the first by a 1-1 
replacement of the individuals involved. Similarly, (2nd-level) cardinality properties and the (2nd-level) properties of being reflexive, symmetric, and transitive do not distinguish replacements of (1st-level) properties and relations induced by 1-1 replacements of the underlying individuals. The same holds for operations such as complementation, union, intersection, and so on. Precisifying (using the resources of contemporary set theory), we may say that formal properties are invariant under isomorphisms. For example, a 2nd-level property $\mathrm{F}$ is formal iff for any isomorphic structures $<\mathrm{A}, \mathrm{B}\rangle$ and $\left\langle\mathrm{A}^{\prime}, \mathrm{B}^{\prime}\right\rangle$, $F$ holds of $B$ in $A$ just in case it holds of $B$ ' in $\mathrm{A}^{\prime}{ }^{30}$

Now, it is easy to see that physical, biological, and other types of properties have a weaker degree of invariance than formal properties. (For example, physical properties do distinguish between mathematical and physical individuals, but formal properties do not.) As a result, the laws governing formal properties apply in physics, but the laws governing physical properties do not apply in our theories of the formal (mathematics and logic). The greater the degree of invariance of a given property, the greater the scope of its laws, and the greater their scope, the greater their normativity. Chemistry distinguishes between molecules with 2 oxygen atoms and 3 oxygen atoms, but logic does not distinguish between molecules with oxygen atoms and molecules with hydrogen atoms, unless they are formally distinguishable. Physics and chemistry are subject to, affected by, and therefore care about, errors identified by logic (i.e., formal errors), but logic is not affected by errors in physics or chemistry (with the exception of physical/chemical errors that have their roots in formal errors).
To repeat: Logical consequences are grounded in formal laws governing the world-laws of identity, cardinality, complementarity, union, intersection, etc.- and the especially strong degree of invariance of these laws is the source of their especially strong normativity. ${ }^{31}$

Conclusion: Whether we recognize the normativity of logic partly depends on our perspective. If we think of logic (or of normativity) as so special that if logic were to be normative, we would be absolutely bound to follow its claims (regardless of circumstances), we are likely to conclude that it is not normative for us. And if we think of it only in the context of our everyday decision making, where questions of preference are more dominant than questions of correctness, we also tend to overlook its normative force. It is when we balance our perspective on logic - recognizing both its limited power on us in contexts where multiple norms compete for our attention and its crucial importance when correctness is at stake, that we come to appreciate its considerable yet less than absolute normative power.

It is clear that one's view on the normativity and plurality of a given subject-matter largely depends on the details of one's theory. But what we have seen in this paper is that it also significantly depends on one's methodology. A deflationist methodology curtails our discernment of plurality as well as normativity, and a platitudinous methodology sets weak constraints on the extent of plurality. A substantivist methodology, in contrast, encourages attentiveness to both normativity and plurality, while setting significant constraints on the scope of pluralism.

University of California, San Diego 


\section{NOTES}

This paper is based on a talk I gave at the Pluralism and Normativity workshop at the University of Bologna, 2015. I would like to thank Sebastiano Moruzzi, Paolo Leonardi, Filippo Ferrari, Nikolaj Pedersen, and Jeremy Wyatt for inviting me to present a talk at the workshop and the audience for stimulating comments. I am also thankful to two referees of American Philosophical Quarterly for comments that helped improve the paper.

1. All these authors have written on truth and/or logic in other books or papers as well, and others have also written on these topics. But to make the discussion manageable I will limit myself to these writings as much as possible.

2. This scenario underlies Lynch's and Pedersen's discussion of the issue.

3. See Sher $(2004 ; 2016 a)$.

4. Here "p" stands for a proposition, but for the purpose of the present discussion we do not have to limit ourselves to propositions as truth-bearers. Statements, sentences, judgments, utterances, beliefs, and even theories will do. We will thus read (E) as representing:

$\left(\mathrm{E}^{*}\right)<\mathrm{p}>$ is true iff $\mathrm{p}$,

where the interpretation of "p" and " $<\mathrm{p}>$ " changes along with one's conception of truth bearers.

Wyatt (2016) distinguishes two ways in which Horwich's theory of truth could be said to be deflationist: (i) it allows no room for a constitution theory for truth, and (ii) it says that truth plays no explanatory role. On my understanding, Horwich's theory is deflationist in both ways, though I prefer to construe (i) more broadly than above. I would say that Horwich's theory is deflationist both in the sense that it does not allow any non-trivial explanation of truth and in the sense that it does not allow any non-trivial role for truth in the explanation of any other philosophically significant subject-matter.

5. I do not take it for granted that all fields of knowledge are in the scope of truth, or, if one assumes that knowledge requires truth, that all fields of discourse are fields of knowledge. In this paper I assume that the empirical sciences lie within the scope of truth and, based on investigations in Sher (2016a and elsewhere), that mathematics and logic do as well. I tend to think that philosophy lies within its scope, but I leave it completely open (a topic of future investigations) whether ethics and aesthetics do. "Fields of knowledge in the scope of truth" includes "fields of discourse in the scope of truth." To abbreviate, I sometimes use "fields of knowledge," "fields of truth", and "domain of truth", and even just "fields" or "domain."

6. "Material truth" is understood in different ways by different philosophers. My understanding is similar to Tarski's (1933). Here, however, one can simply identify "material" with "non-logical truth." The equivalence schema, (E), is an example of a material principle of truth.

7. It is important to distinguish Horwich's view that "truth" is not a logical notion from his view that "the truth predicate exists solely for the sake of a certain logical need" (Horwich 1990: 2, my italics). The so-called "logical" need that Horwich refers to is the need to make statements that we are not in a position to make either due to ignorance or due to some technical problem. (See examples in Part II, A.) The reason Horwich calls this a "logical" need is that he regards the problem in question as "especially common in logical and philosophical contexts" (Horwich 1990, 3). Another reason might be that this is a largely technical problem. On the other hand, the reason (or one reason) that "truth"/ truth is in fact not a logical notion/property is that, unlike logical notions/properties, it does not satisfy the invariance-under-isomorphism criterion of logicality (see Sher 2016a; Wyatt 2016).

Deflationists tend to favor the proof theoretic approach to logic over the semantic approach. They may view this as license to disregard the notion of logical truth. 


\section{2 / AMERICAN PHILOSOPHICAL QUARTERLY}

8. I might add that I use "substantive" as an informal term rather than as a term-of-art that requires a rigid definition. In Witgensteinian terminology, I regard "substantive" as a representative of a family of concepts bearing resemblance to each other. This family includes "substantive" itself (in the everyday sense of the word) as well as other concepts such as "informative," "explanatory," and so on. Ceteris paribus, the more elements in this family a given account or a theory falls under, the more strongly substantive it is. For more on my view of substantiveness, see Sher (2004; 2016a; 2016b).

9. There are other differences between Wright and Lynch as well, for example, with respect to the question whether there is a general truth property. Here I focus on issues that are especially relevant to the present investigation.

10. For the status of "truth" in this sentence see the last two paragraphs in the introductory section of this paper. What I am saying here is, roughly, that in order to find out what the thing that would fruitfully be called "truth" (given the variety of current practices) is, I will start with the need for something like it in knowledge.

11. There are other views that associate truth with the world. Wright (1992), for example, mentions the response dependence view, which was originally designed to deal with secondary qualities and what our response to them depends on. Although it is possible to extend this view to the context of truth, its focus is on something different from the point at hand, which is getting the world right.

12. This view sets significant constraints on the applicability of truth to areas that I do not consider here, such as ethics and aesthetics. (See fn. 5 above.) But given my flexibility with respect to patterns (routes, forms) of correspondence and my policy of "looking and seeing" (rather than deciding apriori or in advance) how correspondence behaves in different areas, the possibility that truth applies to ethics/ aesthetics is by no means ruled out. (As I indicated earlier, this is a topic for a future investigation.)

13. For an example of a complex, indirect route of correspondence, see the account of mathematical truth in Sher $(2015 ; 2016 a)$.

14. Note: (i) Even very weak substantivism with respect to the general principles is not tantamount to deflationism. The deflationist requirement that truth be exhausted by a single, very weak, general principle (i.e., truth is exhausted by the (E) schema) is rejected by the substantivist approach (regardless of how it is worked out). (ii) Although substantivism is open to pluralism, it is compatible with monism. An example of a substantivist who does not endorse any kind of pluralism is David (1994).

15. See also Carnap (1950).

16. Another example: if the world is governed by a formal law which says that having a property which is included in another property necessitates having the latter property, then this rules out a logic $\mathrm{L}$ that advocates the rule: $\mathrm{Aa},(\forall \mathrm{x})(\mathrm{Ax} \supset \mathrm{Bx}) \Rightarrow \sim \mathrm{Ba}$.

17. To give a sense of the scope of formal possibility in Sher (2016a) I might indicate that it is broader than metaphysical possibility. For example, a situation in which a given object is both all red and yellow is formally-possible but, on at least some conceptions of metaphysical possibility, it is metaphysically impossible.

18. " $p$ " is true iff $p$, where " $p$ " is a quotational name of " $p . "$

19. Another way to achieve this is to use substitutional quantification.

20. Right about the close relation between normative concepts and "ought," though not necessarily about the precise way in which they are related ("a person can fully possess [a normative concept] only in virtue of deploying the concept OUGHT." (See above.)).

21. See an excellent explanation of this point in MacFarlane (2002).

22. For a more detailed discussion see Sher (2016a). 
23. Engel, too, emphasizes the epistemic significance of truth: "truth is a norm of belief" and many "of our epistemic norms are grounded in this [norm]" (Engel 2001, 38).

24. Such a standpoint is human rather than Godly, and as such it is not subject to objections like those raised by Putnam (1983). One example of such a standpoint is that of a Tarskian metalanguage, which is more powerful than its (immanent) object-language, yet still utterly human. It should be noted that a Tarskian metalanguage is also immanent, and as such its own statements raise the question of truth, requiring further transcendence. (Infinite regress becomes harmless if we adopt a holistic epistemic methodology (see Sher 2016a)).

25. The normative transcendent standpoint is not limited to questions of truth. It is also the standpoint of questions of, say, justification. But it is essential for truth and, as we will see next, truth is essential for justification.

26. How do we avoid "explosion" in this case, if we adhere to classical logic? By qualifying our claims about the character of, say, light, or better yet, by explaining its dual character as particle and wave. This enables us to avoid direct inconsistency without denying the logical tension, which may play a significant role in guiding our future development or revision of the theory.

27. I have considered the normativity of logic not as binding individual persons in their everyday lives but as binding our theories of the world and us as their creators. And I have not required a full and absolute compliance for something to be a norm. If we approach the logical norms as primarily applied to individual agents in their everyday life, one solution, discussed by Steinberger (2017) following MacFarlane (2014), is using so-called bridge principles. Since in this paper I do not approach the logical norms in this way, I will not discuss this solution here. The interested reader is referred to the above sources.

28. There are two points here: (i) Often, a systematization/precisification of a complex subject-matter comes with a price. This applies to a systematization/precisification of logic as much as knowledge, reality, morality, rationality, etc. Even in mathematics, systematizations/precisifications of number, set, the continuum, etc. come with a price. (ii) Whereas all systematizations/precisifications of logic require measures against Russell's paradox, there could be various ways of avoiding the paradox, not all of which involve limitation of size, which underlies Field's challenge.

29. I should note that it might also be possible to challenge Field's conclusion directly. McGee (2004), for example, points out that one possible ramification of the reflection principle (see e.g., Lévy 1960) is that "the universe of pure sets is so large and structurally variegated that every structural property of the universe as a whole is already exemplified at some ordinal level of the set-theoretic hierarchy" (McGee 2004, 379).

30. Terminology: (i) In a structure $<A, B>$, $A$ is the universe (a non-empty set of individuals) and $B$ is a subset of $\mathrm{A}$ (the extension of some 1st-level property in $\mathrm{A}$ ). (ii) $<\mathrm{A}, \mathrm{B}\rangle$ and $\left\langle\mathrm{A}^{\prime}, \mathrm{B}^{\prime}\right\rangle$ are isomorphic iff there is a 1-1 and onto function $f$ from $\mathrm{A}$ to $\mathrm{A}^{\prime}$, such that $\mathrm{B}^{\prime}$ is the image of $\mathrm{B}$ under $f$.

31. In Sher (2016a) I show how strong invariance is also connected to other features of logic: its strong generality, modal force, topic neutrality, quasi-apriority, and so on.

\section{REFERENCES}

Beall, JC and Greg Restall. 2006. Logical Pluralism (Oxford: Oxford University Press).

Carnap, Rudolf. 1934. The Logical Syntax of Language (London: Routledge \& Kegan Paul). . 1950. "Empiricism, Semantics, and Ontology," Meaning and Necessity (Chicago: Chicago

University Press), 205-221. 


\section{4 / AMERICAN PHILOSOPHICAL QUARTERLY}

David, Marian. 1994. Correspondence and Disquotation (Oxford: Oxford University Press).

Dummett, Michael. 1963. "Realism." Truth and Other Enigmas (Cambridge, MA: Harvard University Press), pp. 145-165.

Engel, Pascal. 2001. "Is Truth a Norm?" in Interpreting Davidson, ed. P. Kotatko and P. Pagin. (Stanford: CSLI), pp. 37-51.

Field, Hartry. 2009. "Pluralism in Logic," Review of Symbolic Logic, vol. 2, 342-359.

Frege, Gottlob. 1893. The Basic Laws of Arithmetic I (Berkeley: California University Press).

Harman, Gilbert. 1986. Change in View (Cambridge, MA: MIT Press).

Horwich, Paul. 1990. Truth (Oxford: Blackwell).

. 2018. “Is TRUTH a Normative Concept?' Synthese, vol. 195, pp. 1127-1138.

Korsgaard, Christine. 1996. The sources of Normativity (Cambridge: Cambridge University Press).

Lévy, Azriel. 1960. "Axiom Schemata of Strong Infinity in Axiomatic Set Theory," Pacific Journal of Mathematics, vol. 10, pp. 23-38.

Lynch, Michael. 2009. Truth as One and Many (Oxford: Oxford University Press).

MacFarlane, John. 2002. "Frege, Kant, and the Logic in Logicism," Philosophical Review, vol. 111, pp. 25-65.

2014. Assessment Sensitivity (Oxford: Oxford University Press).

McGee, Vann. 2004. “Tarski’s Staggering Existential Assumptions." Synthese, vol. 142, pp. 371-387.

Pedersen, Nikolaj 2014. "Pluralism ×3: Truth, Logic, Metaphysics." Erkenntnis 79, pp. 259-277.

Putnam, Hilary 1983. Realism and Reason. Cambridge: Cambridge University Press.

Sher, Gila 1996. “Did Tarski Commit ‘Tarski's Fallacy'?” Journal of Symbolic Logic 61, pp. 653-686. 2004. "In Search of a Substantive Theory of Truth." Journal of Philosophy 101, pp. 5-36

2013. "The Foundational Problem of Logic." Bulletin of Symbolic Logic 19, pp. 145-198.

2015. "Truth as Composite Correspondence." Unifying the Philosophy of Truth, ed. Theodora Achourioti et al. (Dordrecht: Springer), pp. 191- 210.

2016a. Epistemic Friction: An Essay on Knowledge, Truth, and Logic, (Oxford: Oxford University Press).

—. 2016b. "Substantivism about Truth." Philosophy Compass 11, pp. 818-828.

Steinberger, Florian. 2017. "The Normative Status of Logic." Stanford Encyclopedia of Philosophy. https://plato.stanford.edu/archives/spr2017/entries/logic-normative/.

Tarski, Alfred. 1933. "The Concept of Truth in Formalized Languages," in Tarski (1983), pp. 152-278. 1936. "On the Concept of Logical Consequence," in Tarski (1983), 409-420.

- 1983. Logic, Semantics, Metamathematics (Indianapolis: Hackett).

Wright, Crispin. 1992. Truth and Objectivity (Cambridge, MA: Harvard University Press).

Wyatt, Jeremy. 2016. "The Many (Yet Few) Faces of Deflationism," Philosophical Quarterly, vol. 66, pp. 362-382. 